\title{
REVESTIMENTOS ALTERNATIVOS NA CONSERVAÇÃO PÓS-COLHEITA DE MARACUJÁ-AMARELO ${ }^{1}$
}

\author{
LYA JANUÁRIA BEIRUTH DA SILVA², MARIA LUZENIRA DE SOUZA ${ }^{3}$, \\ SEBASTIÃO ELVIRO DE ARAÚJO NETO4, ANA PAULA MORAIS ${ }^{5}$
}

RESUMO - Este trabalho objetivou avaliar diferentes substancias: cera de carnaúba, látex de seringueira, cloreto de cálcio e fécula de mandioca na conservação pós-colheita do maracujá-amarelo armazenado sob temperatura ambiente. Frutos colhidos, selecionados, lavados e sanitizados com água clorada a $150 \mathrm{mg} \mathrm{L}^{-1}$ foram submetidos aos seguintes tratamentos: 1 - controle, lavados e sanitizados; 2 - cera de carnaúba; 3 - látex de seringueira diluído 1:3 (v/v); 4 - cloreto de cálcio a 1\%; 5 - fécula de mandioca a 2\%. O delineamento utilizado foi o inteiramente casualizado em parcelas subdivididas, sendo a parcela principal formada pelo tempo de armazenamento, e as subparcelas pelos tratamentos, com 3 repetições de 4 frutos cada. O revestimento do maracujá-amarelo com cera de carnaúba, látex de seringueira, cloreto de cálcio e fécula de mandioca não influenciou nos resultados de massa fresca do fruto e da polpa, AT, SS, SS/AT e ácido ascórbico. O látex de seringueira, semelhantemente ao produto comercializado cera de carnaúba foram as coberturas mais eficientes, reduzindo a perda de massa e o índice de murchamento, e aumentando em 4 e 3 dias, respectivamente, a vida de prateleira dos frutos.

Termos para indexação: Passiflora edulis f. flavicarpo; amido de mandioca; cera de carnaúba; cloreto de cálcio; látex de seringueira.

\section{ALTERNATIVE COVERING IN THE SHELF LIFE CONSERVATION OF YELLOW PASSION FRUIT PRODUCED IN ORGANIC SYSTEM}

\begin{abstract}
The present work had the objective to evaluate different substances: carnauba's wax, latex rubber tree, solution of calcium chloride and cassava starch in the shelf life of the yellow passion fruit stored under temperature atmosphere. Fruits selected, washed and sanitized with chlorinated water in $150 \mathrm{mg} \mathrm{L}^{-1}$, were submitted by the following treatment: 1 - control, washed and sanitized; 2 - immerse in carnauba's wax (Fruit Wax); 3 - immerse in rubber tree latex, diluted in proportion of $1: 3(\mathrm{v} / \mathrm{v}) ; 4$ - solution of calcium chloride in $1 \%$; 5 - cassava starch in $2 \%$. The experimental design was completely randomized in split-plot arrangement. The plot corresponded to the storage period (0, 3, 6, 9, 12 and 15 days) and the split-plot by the treatments, with 3 repetitions of 4 fruits each. The fresh weight of the fruit, fresh weight of the pulp, titratable acidity (TA), soluble solids (SS), ratio SS/TA and ascorbic acid of the yellow passion fruit was not affected by the coating with Fruit Wax, rubber tree latex, calcium chloride and cassava starch. The rubber tree latex, similar to the product commercialized as carnauba's wax was the most efficient coating, reducing the mass loss and the shriveling index and increasing in 4 and 3 days, respectively the shelf life of the fruits.

Index terms: Passiflora edulis f. flavicarpa; cassava starch; carnauba's wax; calcium chloride rubber trees latex.

\section{INTRODUÇÃO}

O Estado do Acre apresenta uma das mais baixas produções frutícolas do País e não atende à demanda interna e, por consequência, importa frutas de outras regiões produtoras. Segundo Ledo (1996), essa baixa produção no Acre é causada por vários fatores, principalmente pela falta de uma política agrícola específica e de tecnologias adaptadas para a região.

Quando há tecnologia validada para determinada atividade agrícola, geralmente é de difícil acesso, por causa do isolamento aos grandes centros.

O maracujá-amarelo é um fruto altamente perecível após o seu desligamento da planta, o que o predispõe a uma rápida desidratação do pericarpo acompanhada de murchamento, reduzindo, assim, seu período de conservação e comercialização (Enamorado et al., 1995; Durigan et al., 2004). Esta
\end{abstract}

1(Trabalho 252-08). Recebido em: 03-10-2008. Aceito para publicação em: 21-08-2009.

${ }^{2}$ Eng $^{\mathrm{a}}$. Agr ${ }^{\mathrm{a}}$. M. Sc. em Agronomia (Produção Vegetal), Universidade Federal do Acre (UFAC), Rio Branco, Acre, E-mail: lyabeiruth@yahoo.com.br

${ }^{3}$ Eng $^{\mathrm{a}}$. Agr ${ }^{\mathrm{a}}$. Dr ${ }^{\mathrm{a}}$. em Tecnologia de Alimentos, UFAC, Rio Branco, Acre. E-mail: mluzen@hotmail.com

${ }^{4}$ Eng $^{\circ}$. Agr ${ }^{\circ}$. Doutor em Fitotecnia, UFAC, Rio Branco, Acre. E-mail:selviro2000@yahoo.com.br

${ }^{5}$ Eng $^{\mathrm{a}}$. Agr ${ }^{\mathrm{a}}$. Universidade Federal do Acre, Rio Branco, Acre. E-mail: apmorais@ufac.br 
perda na qualidade ocorre por causa da atividade respiratória intensa e da perda significativa de água, que dependem das diferenças na temperatura e umidade relativa e no diferencial de pressão do vapor de água entre a atmosfera e o produto (Fonseca et al., 2000).

Para prolongar o período de armazenamento dos frutos, é necessário utilizar técnicas de conservação que interfiram nos processos fisiológicos, reduzindo as taxas de transpiração e respiração, por meio da diminuição da temperatura, elevação da umidade relativa do ar, uso de aditivos na superfície e de embalagens adequadas, uma vez que a aparência é o critério mais utilizado pelo consumidor para avaliar a qualidade de frutas e hortaliças (Chitarra \& Chitarra, 2005).

Materiais de cobertura tipo ceras ou lipídios e derivados podem ser aplicados na forma de emulsão estável, microemulsão com água ou diretamente no produto, quando ainda fundidos (Chitarra \& Chitarra, 2005), com a finalidade de manter a qualidade e elevar a vida de prateleira.

O látex é uma dispersão coloidal estável de uma substância polimérica em um meio aquoso. É praticamente neutro, com pH de 7,0 a 7,2, mas quando exposto ao ar por um período de 12 a 24 horas, o pH cai para 5,0 e sofre coagulação espontânea, formando o polímero que é a borracha (Wikipédia, 2007), e não é comumente utilizado como cobertura de frutos, mas por ser natural, energia renovável, facilmente disponível na região, e com baixo preço, motivos que estimulam testá-lo como cobertura de frutos.

A aplicação de sais de cálcio pode aumentar os níveis de cálcio no fruto e proporcionar maior resistência na parede celular, dificultando a ação de enzimas pécticas, promovendo maior integridade às células, com consequente controle das desordens fisiológicas e aumento da vida útil dos frutos (Pinheiro et al., 2005).

O amido extraído da mandioca também pode ser utilizado como revestimento por apresentar boas características para formação de películas que, além de serem comestíveis, são de baixo custo quando comparadas às ceras comerciais. A obtenção de película de fécula de mandioca baseia-se no princípio da gelatinização do amido, que ocorre acima de 70 ${ }^{\circ} \mathrm{C}$ com excesso de água, que, após resfriado, forma uma película transparente e resistente, devido a suas propriedades de retrogradação, sendo facilmente removido com água (Nunes et al., 2004).

Portanto, as substâncias utilizadas como revestimento, neste trabalho, apresentam potencial para aplicação em frutas como o maracujá, incorpo- rando, com isso, aspectos regionais e econômicos na conservação pós-colheita de frutas.

Neste contexto, o objetivo deste trabalho foi avaliar diferentes substâncias: cera de carnaúba, látex de seringueira, cloreto de cálcio e fécula de mandioca na conservação pós-colheita do maracujá-amarelo armazenado sob temperatura ambiente.

\section{MATERIAL E MÉTODOS}

O experimento foi conduzido na Unidade de Tecnologia de Alimentos da Universidade Federal do Acre - UFAC, em Rio Branco-AC. Os frutos de maracujá-amarelo utilizados foram provenientes da unidade de produção orgânica, no Projeto de Assentamento Dirigido Humaitá, no sudeste acriano e da unidade experimental da UFAC.

Os frutos foram coletados em janeiro de 2007, frutos com 60 a $80 \%$ de casca de cor amarela contendo $2 \mathrm{~cm}$ de pedúnculo, isentos de danos profundos e podridões; no entanto, alguns apresentaram verrugose superficialmente. Não foi utilizado nenhum tratamento pré-colheita para controle de doenças e pragas.

Após a coleta, os frutos foram selecionados, eliminando-se aqueles com danos físicos, mecânicos e biológicos, lavados com água corrente para a remoção das sujidades e sanificados com água clorada a $150 \mathrm{mg} \mathrm{L}^{-1}$, durante 5 minutos, e secos ao ar. Os frutos foram divididos em cinco grupos para aplicação dos 5 tratamentos. $\mathrm{T}_{1}$ (Controle) - Frutos sem aplicação de revestimento/cobertura; T2 - Cera de Carnaúba (Fruit Wax) (18\% a 21\% de cera de carnaúba) - Após lavagem e sanificação dos frutos, a cera de carnaúba foi aplicada manualmente, de forma a cobrir toda a superfície das frutas com uma fina camada. Com o auxílio de uma pipeta graduada de $1 \mathrm{~mL}$, foi depositado $0,20 \mathrm{~mL}$ de cera em cada fruto, espalhando-se uniformemente. Este volume aplicado corresponde a 1,6 L de cera por tonelada de fruto; $\mathrm{T}_{3}$ (Látex de seringueira) - O látex foi diluído com água destilada na proporção de 1:3, e cada fruto foi imerso 3 vezes na solução, de forma a cobrir toda a sua superfície com uma fina camada; $\mathrm{T}_{4}$ (Cloreto de cálcio) - Os frutos foram imersos em solução de cloreto de cálcio $\left(\mathrm{CaCl}_{2}\right)$ a 1\% durante 20 minutos; $\mathrm{T}_{5}$ (Fécula de mandioca) - A formulação a $2 \%$ foi obtida através da adição de 40 g de fécula em água e o volume completado para $2 \mathrm{~L}$, sob aquecimento e agitação constante até $70{ }^{\circ} \mathrm{C}$ para geleificação. Após o resfriamento, cada fruto foi imerso 3 vezes na solução, de forma a cobrir toda a sua superfície com uma fina camada.

Os frutos de cada tratamento foram armaze- 
nados em sala fechada no laboratório de alimentos da UFAC, arejada e sob temperatura e umidade relativa ambiente de $26 \pm 3^{\circ} \mathrm{C}$ e 85-90\%, durante 15 dias.

No dia de aplicação dos tratamentos e a cada três dias, durante 15 dias, foram retiradas amostras dos tratamentos para análise das seguintes características: a) rendimento de polpa dos frutos em porcentagem-por meio dos valores da massa fresca do fruto com casca e massa da casca do fruto; b) índice de enrugamento obtido por meio de uma escala de avaliação de 0 a 5 , relacionando a perda do volume ao grau de enrugamento visual dos frutos, em que: perda do volume $0=0 \% ; 1=3 \%$; $2=6 \%$; $3=9 \% ; 4=12 \% ; 5$ 15\% (Mota et al., 2003); c) sólidos solúveis em ${ }^{\circ}$ Brix por meio da leitura direta em refratômetro óptico, com leitura na faixa de 0 a 32 Brix; d) acidez titulável determinada pela titulação da amostra com hidróxido de sódio ( $\mathrm{NaOH}, 0,5 \mathrm{~N})$, expresso em ácido cítrico (AOAC, 1990); e) relação sólidos solúveis/acidez titulável por meio do quociente entre as duas características; f) teor de ácido ascórbico obtido por titulação com iodato de potássio $(0,1 \mathrm{~N})$ e expresso em mg $100 \mathrm{~g}^{-1}$, segundo as normas analíticas do Instituto Adolfo Lutz (Brasil, 2005); g) perda de massa da matéria fresca obtida por meio de balança de precisão, pesando sempre os mesmos frutos diariamente, no mesmo horário, e a partir dos valores obtidos foi determinada a perda de massa fresca do fruto, ao longo do período de armazenamento de 15 dias, e expresso em porcentagem.

O delineamento estatístico utilizado foi o inteiramente casualizado, em parcelas subdivididas, sendo a parcela principal formada pelos períodos de armazenamento ( $0 ; 3 ; 6$; 9; 12 e 15 dias), e as subparcelas, pelos tratamentos (5 tipos de coberturas), com 3 repetições de 4 frutos cada.

Os resultados foram analisados por meio de regressão (fator quantitativo) e/ou comparação de médias, pelo teste Tukey, a $5 \%$ de probabilidade do erro (fator qualitativo).

\section{RESULTADOS E DISCUSSÃO}

Os revestimentos aplicados nos frutos influenciaram, de forma isolada, no índice de murchamento, rendimento de polpa e perda de massa (testes F, a 5\% de probabilidade de erro). As demais variáveis não diferiram estatisticamente entre si (Tabela 1).

O tempo de armazenamento influenciou na massa fresca do fruto, índice de murchamento, rendimento de polpa, acidez titulável, relação sólidos solúveis/acidez titulável, teor de ácido ascórbico e perda de massa. Houve efeito da interação entre os revestimentos aplicados e o tempo de armazenamento somente para o índice de murchamento e perda de massa (Figuras 1;2;3 e 5).

A massa fresca do fruto decresceu linearmente 3,3 g ao dia durante o período de armazenamento (Figura 1). Os frutos apresentaram massa fresca inicial (dia zero) de 112,7 g fruto ${ }^{-1}$, e após os quinze dias de observação, 62,8 g fruto-1 ${ }^{-1}$, apresentando um decréscimo de $45 \%$.

A perda da massa do fruto não refletiu em perda da massa da polpa (Figura 1); assim, o aumento no rendimento de polpa, em 1,9 g ao dia (Figura 1), foi decorrente da perda de massa da casca. Este fato fica mais evidente em frutos tratados com cloreto de cálcio que apresentaram maior percentual de rendimento de polpa (41,11\%), sendo também os que mais perderam massa (Figura 2). Silva et al. (1999) relatam que, em frutos de maracujá, o aumento no rendimento de suco em porcentagem deve-se à maior desidratação da casca em relação à polpa.

O peso da polpa aumentou durante o amadurecimento, não só devido ao aumento do volume de água resultante da hidrólise dos carboidratos, como consequência da respiração, mas principalmente devido ao movimento osmótico da água da casca para a polpa. E este aumento é uma das características mais desejáveis, seja na comercialização da fruta in natura, seja para fins industriais, por ser essa a fração de interesse econômico (Chitarra \& Chitarra, 2005).

Essa perda de massa significativa (27,8\%), quase que exclusivamente da casca, favorece o consumidor e a indústria de polpa que ganham em pagar por frutos mais concentrados e com menos água, e perdem o agricultor e o varejista, mesmo que a qualidade da polpa não seja alterada (Tabela 1).

A perda de massa do fruto foi linear e crescente para todos os tratamentos no decorrer do armazenamento. O revestimento com látex de seringueira proporcionou a menor perda de massa durante todo o período de armazenamento, seguido pela cobertura com cera de carnaúba, em que ambos perderam 31,5\% e $17,9 \%$ menos massa que o tratamento controle (Figura 2).

Os revestimentos cera de carnaúba e látex de seringueira foram os mais eficientes na redução da perda de massa do fruto (Tabela 1 e Figura 2). A cera de carnaúba já é muito difundida, comercializada e utilizada na conservação de muitos frutos, inclusive do maracujá (Silva et al., 1999; Mota et al., 2003; Mota et al., 2006). A novidade, neste trabalho, foi a eficiência também na aplicação de látex, que, pela formação de película, pode ter promovido o mesmo efeito que a cera de carnaúba: o de reduzir a respiração dos frutos, induzida pela redução da concentração de $\mathrm{O}_{2}$ e 
aumento de $\mathrm{CO}_{2}$, além de reduzir a perda de água por transpiração e, consequentemente, o murchamento, a produção e a sensibilidade ao etileno, e as reações de oxidação (MOTA et al., 2003).

O valor médio de perda de massa da matéria fresca do fruto revestido com solução de cloreto de cálcio, (31,11\%) não diferiu estatisticamente do tratamento-controle, $(30,08 \%)$ nem dos frutos revestidos com película de fécula de mandioca, (32,85\%) (Tabela 1).

Os resultados obtidos com películas de fécula de mandioca foram semelhantes aos encontrados em pêssegos “Aurora 2" sob atmosfera modificada, com maior perda de massa $(19,72 \%)$ nos tratamentos utilizando solução com 3\% de fécula de mandioca, sendo os frutos imersos por 1 minuto (Nunes et al., 2004), e em manga "Surpresa”, com aumento em 3 dias na vida útil, com aplicação de 3\%, por 3 minutos de imersão (Scanava Júnior et al., 2007). Resultados semelhantes foram encontrados por outros pesquisadores trabalhando com outras frutas e hortaliças. Porém, quando comparada com outros revestimentos, como ceras ou PVC, a fécula de mandioca promove resultados inferiores (Reis et al., 2006).

No presente estudo, o cálcio não foi capaz de minimizar a perda de massa, durante o período de armazenamento dos frutos, uma vez que não diferiu estatisticamente do tratamento-controle. Apesar de a aplicação de 1 e $2 \%$ desta solução, em frutos de maracujá submersos por 20 minutos, reduzir a perda de massa de matéria fresca (Tavares et al., 2003), os resultados podem não ser favoráveis à conservação de maracujá (Silva \& Vieites, 2000).

Segundo Silva et al. (2000), o tratamento com cálcio tem por objetivo retardar e/ou minimizar mudanças que ocorrem durante o armazenamento, como a diminuição da atividade respiratória e a redução da perda de massa da matéria fresca, visto que estes estão em função da transpiração e do consumo de substratos respiratórios.

O fruto de maracujazeiro-amarelo é considerado murcho a partir de uma perda de $8 \%$ do seu peso inicial, por prejudicar a aparência do fruto, depreciando o seu valor comercial (FAEP, 2008). Diante deste fato, observa-se que os frutos revestidos com látex de seringueira atingiram os $8 \%$ de murchamento após 9 dias de armazenamento, 4 dias a mais que o controle, juntamente com o revestimento com cera, que durou 8 dias para atingir o murchamento total, 3 dias a mais que o controle.

Os teores médios de sólidos solúveis encontrados na polpa de maracujá-amarelo não diferiram entre os tratamentos aplicados e durante o período de arma- zenamento. Com valor médio de 14\%, mantiveram-se praticamente constantes ao longo do período de armazenamento dos frutos. Tais valores encontram-se de acordo com o percentual de sólidos solúveis estimado por Durigan et al. (2004) para o suco de maracujáamarelo, que é de 13,8 a 18,5\%.

O teor de açúcares usualmente aumenta com o amadurecimento das frutas por meio de processos biossintéticos ou pela degradação de polissacarídeos ou conversão de ácidos orgânicos (Chitarra \& Chitarra, 2005). Em maracujá, os ácidos orgânicos também são transformados para síntese de compostos voláteis, perdidos após 3 dias de colhidos (Narain \& Bora, 1992).

A acidez titulável reduziu de forma linear com o decorrer do armazenamento (Figura 4). Segundo Chitarra \& Chitarra (2005), a acidez em produtos hortícolas é atribuída, principalmente, aos ácidos orgânicos que se encontram dissolvidos nos vacúolos das células, tanto na forma livre como na combinada com sais, ésteres, glicosídeos, etc. Em alguns produtos, os ácidos orgânicos não só contribuem para a acidez, como também para o aroma característico, porque alguns componentes são voláteis. Os compostos fenólicos também apresentam caráter acídico, podendo, de certa forma, contribuir para a acidez, além da adstringência. O teor de ácidos orgânicos, com poucas exceções, diminui com a maturação das frutas, em decorrência do seu uso como substrato no processo respiratório ou de sua conversão em açúcares. Esta diminuição também é observada em maracujá-amarelo (Bora \& Narain, 1997).

Os açúcares redutores e não redutores e substratos orgânicos em maracujá são consumidos pelo processo de respiração e manutenção dos frutos ao longo do período de armazenamento (Silva et al., 1999; Mota et al., 2006).

A relação sólidos solúveis/acidez titulável aumentou de forma linear com o decorrer do armazenamento (Figura 4). No início do período de armazenamento, a relação SS/AT apresentava um valor médio de 3,03 e, ao final do período, aumentou para 4,91, o que representa um aumento de 56,40\%. Essa relação é uma das formas mais utilizadas para avaliação do sabor, sendo mais representativa que a medição isolada de açúcares ou da acidez, pois dá uma ideia do equilíbrio entre esses dois componentes e indica a doçura dos alimentos; assim, quanto maior for esta relação, maior será a sensação de doçura no paladar (Chitarra \& Chitarra, 2005). Para estes autores, o aumento nas características do "flavor" durante o amadurecimento de frutas ocorre pelo aumento no teor de açúcares simples, decréscimo da acidez, da adstringência e emanação de compostos voláteis. 
Em frutas climatéricas, como o maracujá, o pico da evolução dos componentes voláteis coincide com o pico da atividade respiratória, mas ocorre redução significativa três dias após a colheita com decréscimo na concentração do butanoato de etila e hexanoato de etila (responsáveis pelo aroma adocicado dos frutos) (Narain \& Bora, 1992).

Os teores médios de ácido ascórbico aumentaram (18,5\%) de forma linear com o decorrer do armazenamento (Figura 5). Os teores médios varia-

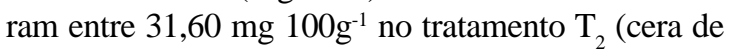

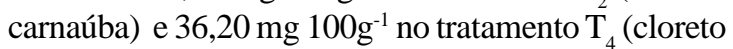

de cácio), sendo a média geral de 33,80 mg $100 \mathrm{~g}^{-1}$ em todo o período de armazenamento.

Para Marchi et al. (2000), o teor de ácido ascórbico das frutas é um parâmetro nutricional de grande importância. Contudo, não se verificam exigências relacionadas ao mesmo no caso de frutas destinadas à industrialização. Embora o ácido ascórbico presente naturalmente na fruta seja relevante sob o ponto de vista nutricional, não é considerado um parâmetro tecnológico indispensável.

TABELA 1 - Valores médios observados, nas características físicas, físico-químicas e químicas de maracujá-amarelo, tratado com diferentes filmes e/ou revestimentos, armazenado sob temperatura ambiente (15 dias a $\left.26 \pm 3^{\circ} \mathrm{C}\right)$. Rio Branco-AC, UFAC, 2007.

\begin{tabular}{|c|c|c|c|c|c|c|c|c|}
\hline \multirow[b]{2}{*}{ Tratamentos } & \multicolumn{8}{|c|}{ Variáveis analisadas } \\
\hline & $\begin{array}{c}\text { MFF } \\
\text { (g) }\end{array}$ & $\begin{array}{c}\text { IM } \\
(0-5) \\
\end{array}$ & $\begin{array}{l}\text { RP } \\
(\%) \\
\end{array}$ & $\begin{array}{l}\mathrm{AT} \\
(\%) \\
\end{array}$ & $\begin{array}{c}\text { SS } \\
\left({ }^{\circ} \text { Brix }\right)\end{array}$ & $\begin{array}{l}\text { SS/ } \\
\text { AT }\end{array}$ & $\begin{array}{c}\text { Ácido } \\
\text { ascórbico } \\
\left(\operatorname{mg} 100 g^{-1}\right)\end{array}$ & $\begin{array}{l}\text { PM } \\
(\%)\end{array}$ \\
\hline $\mathrm{T}_{1}$ - Controle & 93,54 & $3,44 c$ & 39,39ab & $3,79 a$ & $14,29 a$ & $3,96 a$ & $33,02 a$ & $15,51 b c$ \\
\hline $\mathrm{T}_{2}$ - Cera de carnaúba & 101,81 & 2,61ab & $35,06 a$ & $3,70 \mathrm{a}$ & $14,02 \mathrm{a}$ & 3,93a & $31,60 \mathrm{a}$ & 12,53ab \\
\hline $\mathrm{T}_{3}$ - Látex de Seringueira & 104,59 & $2,11 \mathrm{a}$ & $37,28 a b$ & $3,74 a$ & $13,83 a$ & $3,86 a$ & $33,35 a$ & $10,27 a$ \\
\hline $\mathrm{T}_{4}-$ Cloreto de Cálcio & 102,77 & $3,61 \mathrm{c}$ & $41,11 b$ & 3,53a & $14,08 \mathrm{a}$ & $4,17 \mathrm{a}$ & $36,20 \mathrm{a}$ & $16,39 c$ \\
\hline $\mathrm{T}_{5}-$ Fécula de Mandioca & 102,54 & $3,22 b c$ & 39,83ab & $3,74 a$ & $14,14 a$ & $3,95 a$ & $34,83 a$ & $17,17 \mathrm{c}$ \\
\hline Médias & 101,05 & 3,00 & 38,53 & 3,70 & 14,07 & 3,97 & 33,80 & 14,38 \\
\hline CV (\%) & 19,21 & 23,83 & 10,82 & 12,59 & 5,32 & 15,49 & 20,04 & 30,90 \\
\hline
\end{tabular}

(1) Medias seguidas de mesma letra, na coluna, nao diferem sign-ificativamente entre si, ao nivel de $5 \%$ de probabilidade, pelo teste Tukey. MMF - massa fresca do fruto; IM - índice de murchamento; RP - rendimento de polpa; AT - acidez titulável; SS - sólidos solúveis; SS/AT - relação sólidos solúveis/acidez titulável e PM - perda de massa.

- Mas. Fres. do Fruto $y=112,6700-3,3197 x \quad R^{2}=0,62 * *$

- Massa Fresca da Polpa $y=36,529+0,7137 \times \mathrm{R}^{2}=0,17 \mathrm{~ns}$

\ Rendimento de Polpa $\mathrm{y}=31,8+1,923 \times \mathrm{R}^{2}=0,71 *$

- Perda de Massa $\mathrm{y}=6,1313+7,254 \mathrm{x} \mathrm{R}^{2}=0,99 * *$

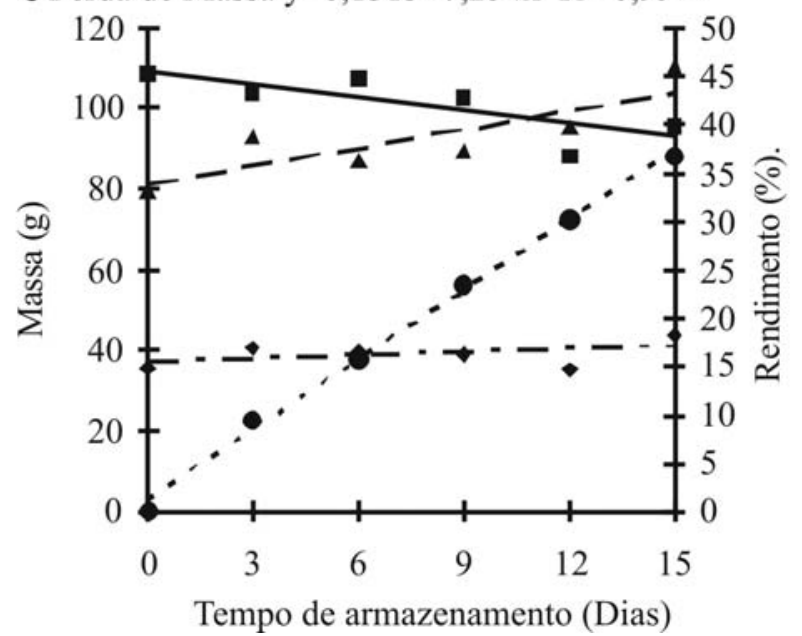

FIGURA 1 - Evolução da massa fresca do fruto (g), massa fresca da polpa (g), rendimento de polpa (\%) e perda de massa (\%) de maracujá-amarelo, tratado com e sem filmes e/ou revestimento, armazenado durante15 dias em condições ambientais (26 oC e 85-90 \% UR) Rio Branco-AC, UFAC, 2007. 


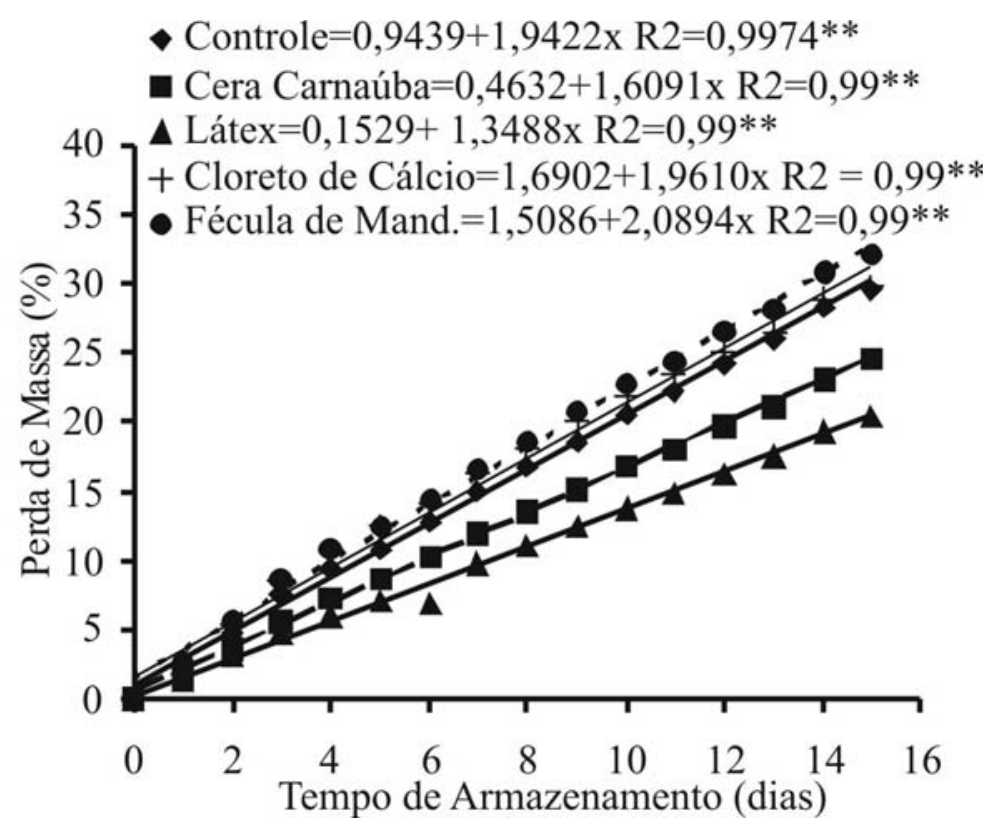

FIGURA 2 - Evolução dos teores médios da perda de massa de maracujá-amarelo, tratado com e sem filmes e/ou revestimento, armazenado durante 15 dias em condições ambientais (26 oC e 85-90 \% UR). Rio Branco-AC, UFAC, 2007.

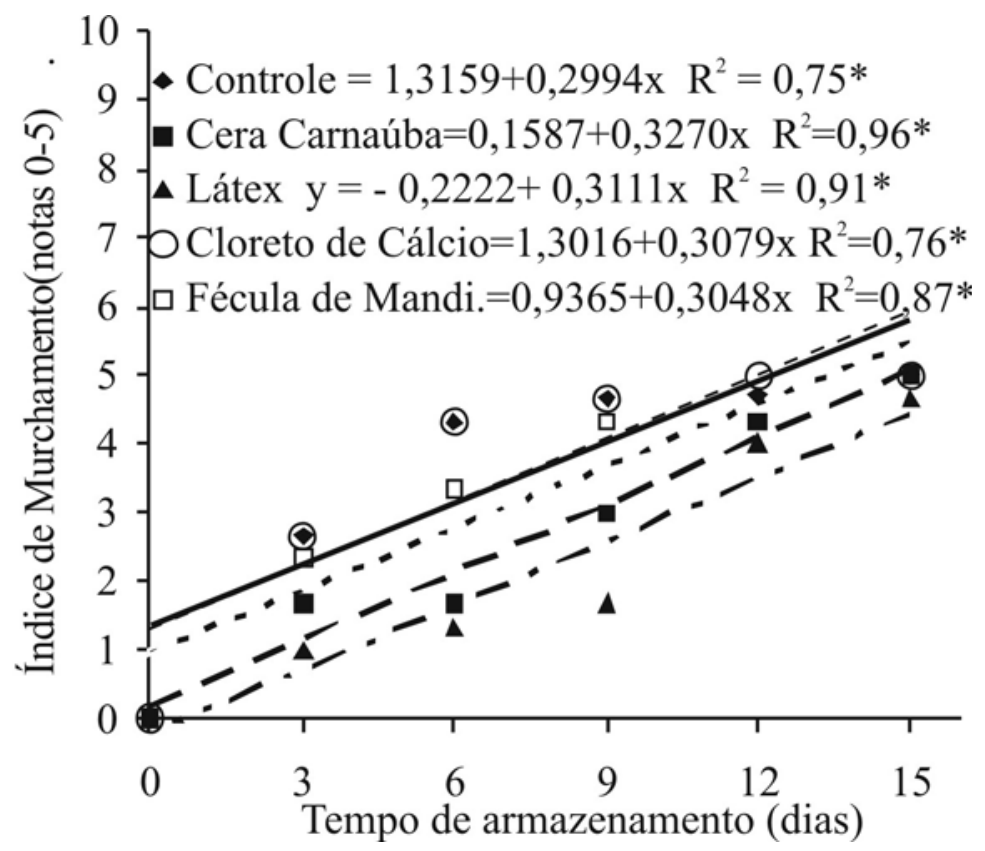

FIGURA 3 - Evolução dos valores médios do índice de murchamento (notas 0-5) de maracujá-amarelo, tratado com e sem filmes e/ou revestimento, armazenado durante15 dias em condições ambientais (26 oC e 85-90 \% UR). Rio Branco-AC, UFAC, 2007. 


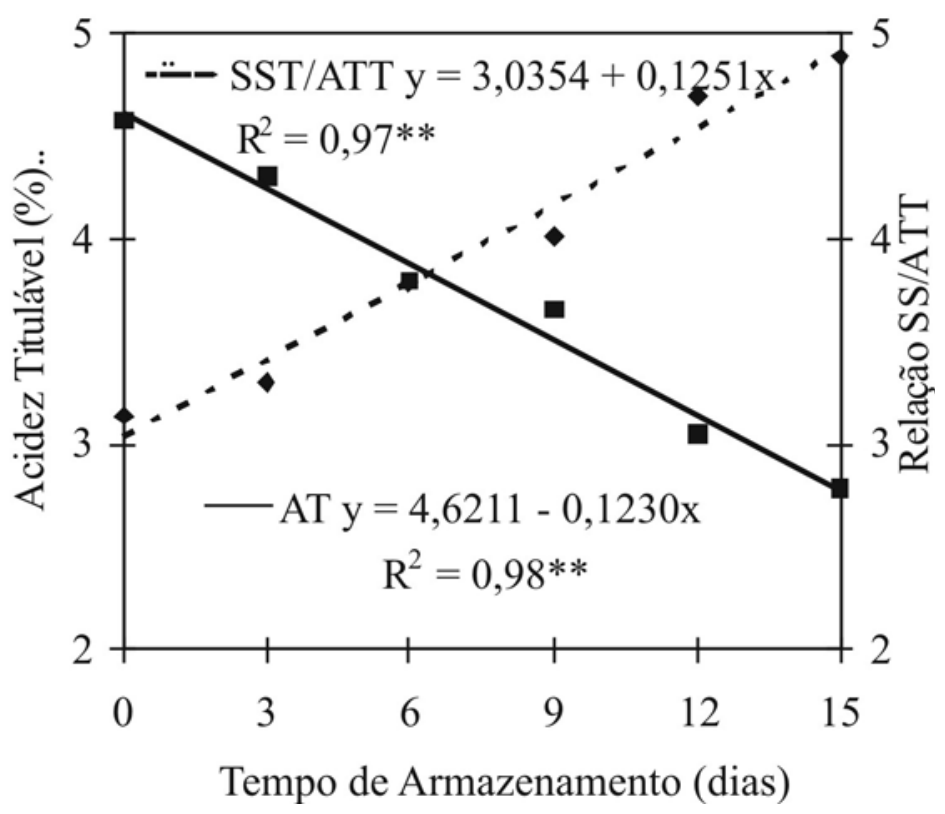

FIGURA 4 - Acidez Titulável - AT (\% ác. cítrico) e Relação Sólidos Solúveis/Acidez Titulável (SS/AT) de maracujá-amarelo, tratado com e sem filmes e/ou revestimento, armazenado durante 15 dias em condições ambientais (26 oC e 85-90 \% UR). Rio Branco-AC, UFAC, 2007.

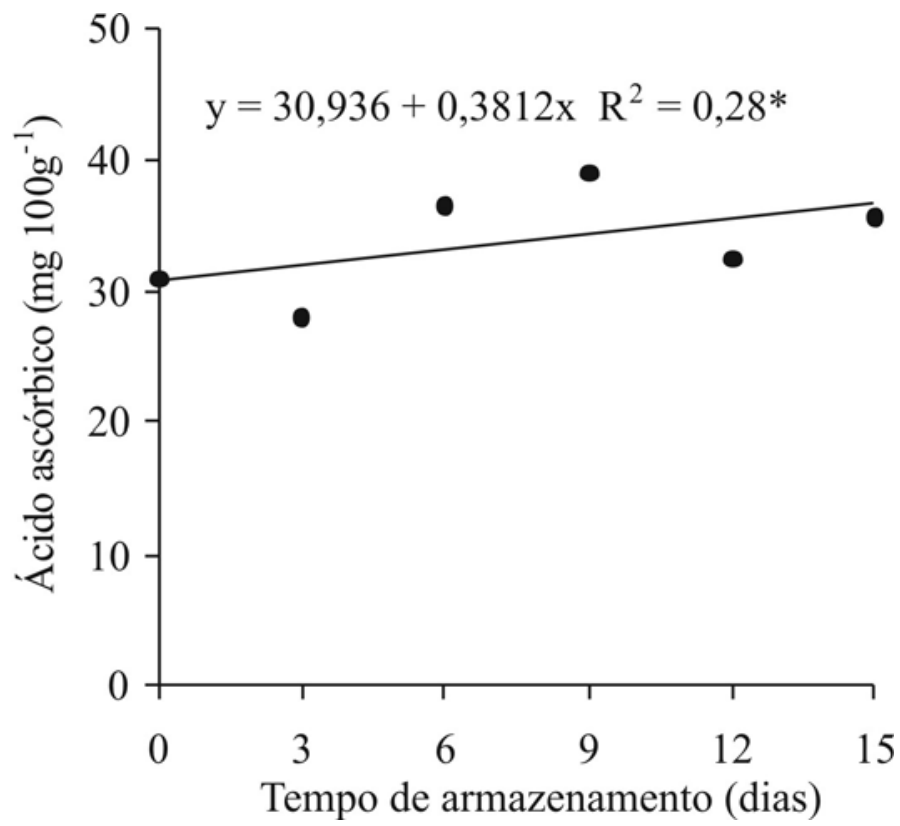

FIGURA 5 - Evolução do teor de ácido ascórbico (mg 100g 1) de maracujá-amarelo, tratado com e sem filmes e/ou revestimento, armazenado durante 15 dias em condições ambientais (26 oC e 8590 \% UR). Rio Branco-AC, UFAC, 2007. 


\section{CONCLUSÕES}

1-O revestimento do maracujá-amarelo com cera de carnaúba, látex de seringueira, cloreto de cálcio e fécula de mandioca não influenciaram na qualidade do fruto.

2-O látex de seringueira, como o produto comercializado cera de carnaúba são mais eficientes, por aumentar em 4 e 3 dias, respectivamente, a vida de prateleira dos frutos.

\section{REFERÊNCIAS}

AOAC - ASSOCIATION OF OFFICIAL ANALITICAL CHEMISTS. Official methods of analysis of the Association of Official Analitical Chemists. 15. ed. Washington, 1990. 2v.

BORA, P. S.; NARAIN, N. Passion fruit. In. MIRA, S. (Ed.) Postharvest physiology and storage of tropical and subtropical fruits. New York: CAB International, 1997. p.375-386.

BRASIL. Ministério da Agricultura. Lei no 10.831, de 23 de dezembro de 2003. Dispõe sobre a agricultura orgânica. Disponível em: <www.agricultura. gov.br>. Acesso em: 09 mar. 2008.

CHITARRA, M. I. F.; CHITARRA, A.B. Pós-colheita de frutas e hortaliças: fisiologia e manuseio. 2. ed. Lavras: UFLA, 2005.

DURIGAN, J. F.; SIGRIST, J. M. M.; ALVES, R. E.; FILGUEIRAS, H. A. C.; VIEIRA, G. Qualidade e tecnologia pós-colheita do maracujá. In: LIMA, A. de A.; CUNHA, M. A. P. (Org.). Maracujá: produção e qualidade na passicultura. Cruz das Almas: Embrapa Mandioca e Fruticultura, 2004. p. 283-303.

ENAMORADO, H. E. P.; FINGER, F. L.; BARROS, R. S.; PUSH-MANN, R.Development and ripening of yellow passion fruit. Journal of Horticultural Science, Arshford, v. 70, n. 4, p. 573-576, 1995.

FAEP - Federação da Agricultura do Estado do Paraná. Classificação do maracujá-amarelo. Disponível em: <http:/www.faep.com.br/comissoes/ frutas/cartilhas/frutas/maracuja.htm>. Acesso em: 10 jan. 2008.
FONSECA, S.C.; OLIVEIRA, F.A.R.; LINO, I.B.M.; BRECHT, J.; CHAU, K.V. Modelling $\mathrm{O}_{2}$ and $\mathrm{CO}_{2}$ exchange for development of perforation-mediated modified atmosphere packaging. Journal of Food Engineering, Exxexi, v. 43, p. 9-15, 2000.

INSTITUTO ADOLFO LUTZ. Normas analíticas: métodos químicos e físicos para análise de alimentos. São Paulo, 1985. v.1, 533p.

LEDO, A. da S. Potencialidade da fruticultura acreana. Rio Branco: EMBRAPA-CPAF/AC, 1996. 16 p. (Documento, 20).

MARCHI, R. de; MONTEIRO, M.; BENATO, E. A.; SILVA, C. A. R. da. Uso da cor da casca como indicador de qualidade do maracujá-amarelo (Passiflora edulis sims. f. flavicarpa deg.) destinado à industrialização. Ciência e Tecnologia de Alimentos, Campinas, v. 20, n. 3, 2000.

MOTA, W. F. da; SALOMÃO, L. C. C.; CECON, P. R.; FINGER, F. L. Waxes and plastic film in relation to the shelf life of yellow passion fruit. Scientia Agricola,Piracicaba, v. 60, n. 1, p. 51-57, 2003.

MOTA, W. F. da.; SALOMÃO, L. C. C.; NERES, C. R. L.; MIZOBUTSI, G. P.; NEVES, L. L. de M. Uso de cera de carnaúba e saco plástico poliolefínico na conservação pós-colheita do maracujá-amarelo. Revista Brasileira de Fruticultura, Jaboticabal, v. 28, n. 2, p. 190-193, 2006.

NARAIN, N.; BORA, P. S. Post-harvest changes in some volatile flavour constituents of yellow passion fruit (Passflora edulis f. flavicarpa). Journal of the Science and Food Agricultural, London, v. 60, n.4, p. 529-530, 1992.

NUNES, E. E.; VILAS-BOAS, B. M.; CARVALHO, G. L.; SIQUEIRA, H. H.; LIMA, L. C. O. Vida útil de pêssegos 'Aurora2' aramazenados sob atmosfera modificada e refrigerada. Revista Brasileira de Fruticultura, Jaboticabal, v. 26, n. 3, p. 438-440, 2004.

PINHEIRO, A. C. M.; VILAS BOAS, E. V. de B.; LIMA, L. C. Influência do $\mathrm{CaCl}_{2}$ sobre a qualidade pós-colheita do abacaxi cv. Pérola. Ciência e Tecnologia de Alimentos, Campinas, v. 25, n. 1, p. 32-36, 2005. 
REIS, K. C.; ELIAS, H. H. S.; LIMA, C. O.; SILVA, J. D.; PEREIRA, J. Pepino-japonês (Cucumis sativus L.) submetido ao tratamento com fécula de mandioca. Ciências Agrotécnica, Lavras, v. 30, n. 3, p. 487493, 2006.

SCANAVACA JÚNIOR, L.; FONSECA, N.; PEREIRA, M. E. C. Uso de fécula de mandioca na pós-colheita de manga "Surpresa". Revista Brasileira de Fruticultura, Jaboticabal, v. 29, n.1, p. 67-71, 2007.

SILVA, A. P. da; VIEITES, R. L.; CEREDA, E. Conservação de maracujá-doce pelo uso de cera e choque a frio. Scientia Agrícola, Piracicaba, v. 56, n. 4, 1999.
SILVA, A. P. da; VIEITES, R. L. Alterações nas características físicas do maracujá-doce submetido à imersão em solução de cloreto de cálcio. Ciência e Tecnologia de Alimentos, Campinas, v. 20, n. 1, 2000.

TAVARES, J. T. de Q.; SILVA, C. L. da; CARVALHO, L. A. de; SILVA, M. A. da; SANTOS, C. M. G.; TEIXEIRA, L. de J.; SANTANA, R. da S. Aplicação pós-colheita de cloreto de cálcio em maracujá amarelo. Magistra, Cruz das Almas, v. 15, n. 1, 2003.

WIKIPÉDIA.AEnciclopédia Livre. Látex. Disponível em: <http://pt.wikipedia.org/wiki/L\%C3\%A1tex>. Acesso em: 27 dez. 2007. 